\title{
The relationship between anthropogenic light and noise in U.S. national parks
}

\author{
Rachel T. Buxton (1) Brett M. Seymoure $\cdot$ Jeremy White $\cdot$ Lisa M. Angeloni • \\ Kevin R. Crooks • Kurt Fristrup • Megan F. McKenna • George Wittemyer
}

Received: 9 January 2020/ Accepted: 23 April 2020/Published online: 7 May 2020

(C) The Author(s) 2020

\begin{abstract}
Context Natural sound and light regulate fundamental biological processes and are central to visitor experience in protected areas. As such, anthropogenic light and noise have negative effects on both wildlife and humans. While prior studies have examined the distribution and levels of light or noise, joint analyses are rarely undertaken despite their potentially cumulative effects.

Objectives We examine the relationship between different types of anthropogenic light and noise conditions and what factors drive correlation, cooccurrences, and divergence between them.
\end{abstract}

Electronic supplementary material The online version of this article (https://doi.org/10.1007/s10980-020-01020-w) contains supplementary material, which is available to authorized users.

R. T. Buxton $(\bowtie) \cdot$ B. M. Seymoure · K. R. Crooks ·

G. Wittemyer

Department of Fish, Wildlife and Conservation Biology,

Colorado State University, Fort Collins,

CO 80523-1474, USA

e-mail: Rachel.Buxton@colostate.edu

R. T. Buxton

Department of Biology, Carleton University, 1125

Colonel By Drive, Ottawa, ON K1S 5B6, Canada

B. M. Seymoure $\cdot$ J. White $\cdot$ L. M. Angeloni

Department of Biology, Colorado State University,

Fort Collins, CO 80523-1878, USA
Methods We overlaid existing geospatial models of anthropogenic light and noise with landscape predictors in national parks across the continental U.S.

Results Overlapping dark and quiet were the most common conditions (82.5-87.1\% of park area), representing important refuges for wildlife and human experience. We found low correlation between anthropogenic light and noise (Spearman's $\mathrm{R}<0.25$ ), with the exception of parks with a higher density of roads. Park land within urban areas had the highest probability of co-occurring high light and noise exposure, while park areas with divergent light and noise exposure (e.g., high light and low noise) were most commonly found 5-20 km from urban areas and in parks with roads present.

Conclusions These analyses demonstrate that light and noise exposure are not always correlated in

\author{
B. M. Seymoure \\ Department of Biology, Washington University in St \\ Louis, St Louis, MO 63130-4899, USA \\ K. Fristrup · M. F. McKenna \\ Natural Sounds and Night Skies Division, National Park \\ Service, 1201 Oakridge Drive, Fort Collins, \\ CO 80525, USA
}


national parks, which was unexpected because human activities tend to produce both simultaneously. As such, mitigation efforts for anthropogenic light and noise will require efforts targeting site-specific sources of noise and light. Protecting and restoring sensory environments will involve constructive partnerships capable of reconciling diverse community interests.

Keywords Anthropogenic light - Cumulative effects · Noise exceedance · Parks · Protected areas . Sensory pollution

\section{Introduction}

Most organisms rely on sound and light for fundamental biological processes (Gaston et al. 2013; Hettena et al. 2014). Thus, the increasingly widespread presence of noise and light pollution alter the most basic sensory functions for an enormous range of organisms (Swaddle et al. 2015). Better understanding of current patterns of noise and light exposure can inform ecologically effective investments in emerging reduction technologies (Lynch et al. 2011; Gaston et al. 2012).

Daily and seasonal cyclic patterns in natural light cue a variety of processes, from gene expression to reproductive behavior (Johnsen 2012). Similarly, sound plays a fundamental ecological role, particularly through behavioral stimuli (Fay and Popper 2000). For example, plant roots use sound to locate water (Gagliano et al. 2017), predators use acoustic cues to locate prey under snow and soil (Montgomerie and Weatherhead 1997; Červený et al. 2011), and most passerine birds use song for courtship and territory defense (Andersson 1994). Because animals rely on both sound and light to orient and communicate, they sometimes respond to the a combination of cues in complex ways (Halfwerk and Slabbekoorn 2015). For example, bats alter their vocal behavior based on both changes in ambient light levels and fluctuations in biological sound levels (Lang et al. 2006). Thus, variation in sound and light conditions across space and time interact to mediate essential behaviors and associated life history traits (Swaddle et al. 2015).

Coping with novel anthropogenic stimuli has led to substantial changes in animal behavior, organismal fitness, altered community structure, and degraded ecosystem function on a global scale (Sih et al. 2011). Noise and light pollution represent some of the most pervasive forms of ecological alteration, propagating far beyond physical habitat alteration (Falchi et al. 2016; Buxton et al. 2017). During the second half of the twentieth century, growth in transportation networks has outpaced human population growth (Barber et al. 2010) and outdoor lighting has grown at a rate of 3 to $6 \%$ per year (Kyba et al. 2017), resulting in the widespread distribution of anthropogenic light and noise (hereafter we use the shorthand ALN; Hölker et al. 2010; Buxton et al. 2017). Literature reviews have documented the substantial threat posed by noise (Shannon et al. 2016) and light (Rich and Longcore 2006; Gaston et al. 2013) to a variety of organisms. For humans, ALN represents a health risk and profound alteration of fundamental human sensory experiences (Chepesiuk 2009).

Anthropogenic light disrupts natural patterns of light through direct effects of illumination and the diffuse spread of sky glow (the scattering of anthropogenic light by aerosols in the atmosphere; Davies et al. 2013). Similarly, anthropogenic noise varies spatially, temporally, and by degree, eliciting different biological responses (Shannon et al. 2016). Diffuse light pollution and chronic noise can mask biologically relevant cues, while direct, localized illumination and transient noise can distract an animal's finite attention or trigger an inappropriate response (e.g., predator avoidance; Francis and Barber 2013; Swaddle et al. 2015; Dominoni et al. 2020).

Anthropogenic activities often produce both noise and light simultaneously; thus, ALN are potentially spatially correlated (Dominoni et al. 2020). However, each pollutant spreads differently across a landscape and thus may become decoupled, especially in protected areas with few internal sources of disturbance. The co-occurrence of ALN could result in cumulative effects. One study found that exposure to boat noise and light had additive effects on antipredator response in hermit crabs (Chan et al. 2010). However, perception in multiple sensory modalities involves complex processes that may not add up linearly and few studies have examined how combinations of pollutants alter animal behavior and physiology (Halfwerk and Slabbekoorn 2015). Because of the potential threat of co-varying ALN, it is important to understand the distribution of these pollutants in 
protected areas and the anthropogenic factors driving their co-occurrence and divergence.

United States National Park Service (NPS) units constitute a diverse range of environmental settings, from wilderness areas to urban parks. Thus, national parks represent a broad range of landscapes to investigate the relationship between ALN. NPS management policies require the conservation and restoration of acoustic and photic (light) resources, which are fundamental to ecological integrity and important for visitor experience (National Park Service 2006). To facilitate management planning, we examine the relationship between ALN in national park units across the continental US. We summarize different types of ALN conditions across and within national park units; investigate the direct relationships between ALN; assess landscape features that drive a positive correlation between ALN; and determine the overall drivers of co-occurrence and divergence of ALN across park landscapes.

\section{Methods}

Anthropogenic light

We used two sources of information to quantify anthropogenic light (hereafter excess light): median upward radiance cloud-free composites from visible infrared imaging radiometer suite (VIIRS) day/night band from July to September 2014 to 2018 (Elvidge et al. 2017) and Zenith sky brightness, or luminance, generated by comparing a sky glow model of VIIRS data with charge-couple device camera observations of sky glow from parks around the U.S. (Falchi et al. 2016). We excluded upward radiance values of $<0.5$ $\mathrm{nW} \mathrm{cm}{ }^{-2} \mathrm{sr}^{-1}$ to control for variation due to natural sources of light (Duriscoe et al. 2018). Upward radiance from VIIRS represents escaped light from localized night-time light sources, such as street lights (hereafter referred to as localized light). Sky brightness, measured in $\mu \mathrm{cd}$ at zenith, represents sky glow or anthropogenic light scattered in the atmosphere producing a diffuse, luminous background that increases terrestrial illumination and obscures views of the night sky (hereafter referred to as diffuse light). All light layers were resampled and projected using bilinear interpolation to match the resolution of noise exceedance layers $(270 \times 270 \mathrm{~m})$. To put light values on a similar logarithmic decibel scale as noise exceedance, we took the $\log$ (base 10) of all light values and multiplied by a constant of 10 .

Anthropogenic noise

To quantify acoustic conditions in national parks within the contiguous U.S., we used estimates of anthropogenic noise (hereafter noise) from a previously published geospatial model (for details see Mennitt and Fristrup 2016). Briefly, models were generated using a Random Forest algorithm that analyzed the relationship between acoustic measurements at 492 sites across the contiguous U.S. and geospatial predictors, such as vegetation, topography, climate, hydrology, and anthropogenic activity. VIIRS radiance was also included as a predictor-the primary input in the sky glow model (see "Anthropogenic light" section). The model generated predictions of existing sound levels. Natural sound levels were predicted by minimizing anthropogenic factors (Mennitt et al. 2014). We used the difference between these values, noise exceedance: an estimate of the amount that anthropogenic sound energy raises the existing sound levels above natural (Buxton et al. 2017).

We used two metrics of noise exceedance: $\mathrm{L}_{90}$, sound levels exceeded $90 \%$ of the time $\left(\mathrm{dB} ; \mathrm{NE}_{90}\right)$ and $\mathrm{L}_{10}$, sound levels exceeded only $10 \%$ of the time $(\mathrm{dB}$; $\mathrm{NE}_{10}$ ). $\mathrm{NE}_{90}$ represents a change in existing sound conditions driven by constant presence of anthropogenic noise (e.g., road traffic), hereafter referred to as chronic noise; and $\mathrm{NE}_{10}$ represents a change in existing sound conditions driven by infrequent anthropogenic noise events (e.g., passing train), hereafter referred to as transient noise.

Thresholds to summarize ALN conditions

We examine the proportion of park area experiencing ALN two-times above natural conditions (except for upward radiance, see below). For noise exceedance, this corresponds to $3 \mathrm{~dB}$, a $50 \%$ reduction in the spatial extent of acoustic signal detection for most vertebrates (i.e., 'listening area'; Barber et al. 2010; Buxton et al. 2017), with consequences for species using acoustic cues to forage, avoid predation, navigate, and attract mates (Brumm 2013). For sky brightness, a doubling of background levels is 174 
$\mu \mathrm{cd}$, which corresponds to twice the light levels of new moon conditions (a light level known to alter the behavior and fitness of several species; Seymoure et al. 2019). Because airglow is variable and transient, little is known about natural or background levels of upward radiance. Instead, because we conservatively set all upward radiance values $<0.5 \mathrm{nW} \mathrm{cm}^{-2} \mathrm{sr}^{-1}$ to zero, we examine park area with non-zero values of upward radiance (Duriscoe et al. 2018).

We summarize the distribution of two types of ALN in national parks: diffuse excess light and chronic noise or diffuse-chronic ALN conditions, and localized excess light and transient noise or localizedtransient ALN conditions. Diffuse-chronic ALN conditions are known to mask important natural stimuli, impairing the discrimination of celestial or lunar cues and impeding the detection of acoustic signals (Dominoni et al. 2020). Localized-transient ALN can result in distraction or misleading, occupying part of an animal's finite attentional capacity or being perceived as a natural signal and provoking an inappropriate response (Chan and Blumstein 2011; Dominoni et al. 2020).

\section{Geospatial features extracted}

We overlaid national park boundaries from the contiguous U.S. (park boundaries updated December 2015; National Park Service 2016) on features known to drive high ALN, including roads, railway lines, urban areas, developed land (where constructed materials constitute $>20 \%$ of land cover), airports, and oil and gas development (Buxton et al. 2017). Matching the spatial resolution of ALN rasters $(270 \times 270 \mathrm{~m})$, we created geoTIFF images of the density, distance to, size, and/or presence of each feature (Table 1). We also extracted the type of land (wilderness areas and park designation), where different types of human use have the potential to affect levels of ALN. We collapsed the 21 park designations into natural resource parks, recreation areas, cultural parks, or national monuments (National Park Service 2003; Comay 2013; Buxton et al. 2019). In statistical analyses, 'national monuments' was used as the reference category. We extracted all ALN values and corresponding landscape variables within national parks, generating a total of $1,528,528$ pixels.
Quantitative analysis

All analyses were performed in R statistical software version 3.5.2 (R Core Team 2019). All code and data are available at https://doi.org/10.6084/m9.figshare. 11410122. Because there were so few non-zero localized excess light values (3.1\% of all raster pixels) and results for most analyses were similar between diffuse-chronic and localized-transient ALN conditions, we excluded localized-transient ALN conditions from further analysis.

To examine the relationship between the diffusechronic ALN in raster cells across park units, we used Spearman's ranked correlation coefficients $(R)$ and $\mathrm{R}^{2}$ values from linear and non-linear models. For nonlinear models we fit second to fourth order polynomials and logistic curves to assess which models had the highest $\mathrm{R}^{2}$.

To determine the influence of landscape features on the correlation between ALN within a park unit, we examined how landscape features in a park (Table 1) relate to Spearman's $R$ values using generalized linear models (GLM) in a multi-model framework. We constructed two model sets. To test the drivers of the degree of positive or negative correlation between ALN, one model set had a Gaussian error structure using $R$ values in each park unit as the response. To test the drivers of the occurrence of positive correlation between ALN, the other had a binomial distribution using a binary variable indicating whether $R$ was greater or less than 0.5 within each park unit. To generate summaries of landscape covariates in each park unit, we took the mean, max, min, and proportion of different landscape features and type of land designation in each park unit (Table 1). To ensure the resulting parameter estimates would be comparable, all landscape variables were scaled by subtracting the mean and dividing by one standard deviation (Schielzeth 2010). To remove collinear landscape covariates we computed a Spearman's correlation matrix and excluded coefficients with an $R>0.5$ that resulted in a model with the lowest Akaike's Information Criterion (AICc; corrected for small sample sizes). We used this model in the dredge function in the MuMIn package (Barton 2013) to generate the top model with the highest Akaike weights. If the weight of the top model was $<0.15$, we averaged models with a $\triangle \mathrm{AICc}>2$ to generate parameter estimates, unconditional standard errors, and $95 \%$ confidence 
Table 1 Sources and attributes of geospatial data layers used to examine the drivers of co-occurrence and divergence of anthropogenic light and noise in U.S. national parks

\begin{tabular}{|c|c|c|c|}
\hline Factors & Details & Park level summary & Data source \\
\hline \multirow[t]{2}{*}{ Light } & Diffuse: sky glow $(\mu \mathrm{cd})$ & \multirow{2}{*}{$\begin{array}{l}\text { Spearman's } \mathrm{R}^{2} \\
\text { between light and } \\
\text { noise }\end{array}$} & $\begin{array}{l}\text { Falchi et al. (2016), New world Atlas global } \\
\text { calibration } \mathrm{k}=0.5\end{array}$ \\
\hline & Localized: upward radiance $\left(\mathrm{nW} \mathrm{cm} \mathrm{cm}^{-2} \mathrm{sr}^{-1}\right.$ ) & & $\begin{array}{l}\text { Visible infrared imaging radiometer suite } \\
\text { (VIIRS) day/night band (DNB, Elvidge } \\
\text { et al. 2017) }\end{array}$ \\
\hline Noise & Noise exceedance $(\mathrm{dB})$ & & Mennitt et al. (2014) and Mennitt (2015) \\
\hline Park area & $\mathrm{km}^{2}$ & Same & gArea (calculated from polygons) \\
\hline Visitation & Average annual visitation (as of 2016) & Same & National Park Service (2015) \\
\hline \multirow[t]{2}{*}{ Urban areas } & Distance to urban area & Min & U.S. Census Bureau (2015a) \\
\hline & Population size of nearby city & Max & ESRI (2014) and U.S. Census Bureau \\
\hline \multirow[t]{2}{*}{ Airports } & Euclidean distance to nearest airport & Min & \multirow{2}{*}{$\begin{array}{l}\text { Federal Aviation Administration (FAA) and } \\
\text { Office of the Assistant Secretary for } \\
\text { Research and Technology's Bureau of } \\
\text { Transportation Statistics (OST-R/BTS) }\end{array}$} \\
\hline & $\begin{array}{l}\text { Enplanements of nearby airport: total number } \\
\text { of passengers boarding aircrafts per year }\end{array}$ & $\operatorname{Max}$ & \\
\hline \multirow[t]{4}{*}{ Roads } & $\begin{array}{l}\text { Road presence a road does not or does intersect } \\
(1 / 0) \text { the raster cell }\end{array}$ & $\mathrm{n} / \mathrm{a}$ & \multirow[t]{4}{*}{$\begin{array}{l}\text { ESRI Streetmap roads (2014) and U.S. } \\
\text { Census Bureau (2015b) }\end{array}$} \\
\hline & $\begin{array}{l}\text { Road density number of raster cells with road } \\
\text { present/total rasters in a park unit }\end{array}$ & Same & \\
\hline & $\begin{array}{l}\text { Road importance type of road: } 6 \text {, freeway; } 5 \text {, } \\
\text { major road (less important than a freeway); } 4 \text {, } \\
\text { other major road; } 3 \text {, secondary road; } 2 \text {, local } \\
\text { connecting road; } 1 \text {, important local road }\end{array}$ & Max & \\
\hline & Distance to road Euclidean distance to road & Min & \\
\hline \multirow[t]{4}{*}{ Oil and gas } & $\begin{array}{l}\text { Oil and gas reserves oil and natural gas } \\
\text { production by basin }\end{array}$ & Mean & \multirow[t]{4}{*}{$\begin{array}{l}\text { Energy Information Administration (2006, } \\
\text { 2007) }\end{array}$} \\
\hline & $\begin{array}{l}\text { Distance to oil wells distance to buffered } \\
\text { polygons around producing wells }\end{array}$ & Min & \\
\hline & $\begin{array}{l}\text { Tight oil and shale gas plays the presence or } \\
\text { absence }(1 / 0) \text { of tight oil and shale gas plays } \\
\text { (significant accumulations of natural gas) in a } \\
\text { raster cell }\end{array}$ & Prop & \\
\hline & $\begin{array}{l}\text { Distance to petroleum refinery Euclidean } \\
\text { distance to refinery }\end{array}$ & Min & \\
\hline $\begin{array}{l}\text { Wilderness } \\
\text { area }\end{array}$ & $\begin{array}{l}\text { The presence or absence }(1 / 0) \text { of a wilderness } \\
\text { area designation in the raster cell }\end{array}$ & $\begin{array}{l}\text { Presence or absence } \\
\text { of wilderness area } \\
\text { in the park unit }\end{array}$ & Eidson (2015) \\
\hline $\begin{array}{l}\text { Park } \\
\text { designation }\end{array}$ & $\begin{array}{l}\text { Natural resource parks, recreation areas, } \\
\text { cultural parks, national monuments }\end{array}$ & & National Park Service (2016) \\
\hline
\end{tabular}

Park level summaries were used to examine the drivers of positive correlation between anthropogenic light and noise in park units, where "same" indicates the same values at a pixel and park level. All raster layers were of $270 \times 270 \mathrm{~m}$ resolution

$k$ atmospheric clarity

intervals (Burnham and Anderson 2002). We considered covariates with large parameter estimates and $95 \%$ confidence intervals that did not overlap zero to be the most influential on the correlation between ALN conditions in parks.
To interpret what landscape features are likely associated with the co-occurrence and divergence of modelled ALN across pixels in park land, given potential non-linear and higher-order interactive effects, we used a random forest variable importance 
approach (RFVI; Breiman 2001) implemented in R packages randomForest (Liaw and Wiener 2002) and rfUtilities (Evans and Murphy 2017). Because diffuse excess light levels were low over the majority of park areas (see "Results" section), to model drivers of cooccurrence and divergence of relatively high noise and excess light in parks without prohibitive zero-inflation, we used the top 25th percentile of diffusechronic ALN values across all park land (hereafter 'co-occurrence or divergence of higher ALN') as thresholds in the RFVI procedure.

We assessed correlation and multicollinearity among predictor variables using Spearman's correlation coefficients and variance inflation factors (VIF), excluding the least relevant covariate to ALN of pairs with an $R>0.5$ and VIF $>3$ (excluded: distance to road and distance to rail line). We generated three models with the following binary response variables: (1) pixels within the highest 25th percentile of both diffuse excess light and chronic noise (higher excess light, higher noise), (2) pixels within the lowest 75th percentile of diffuse excess light and highest 25th percentile of chronic noise (lower excess light, higher noise), and (3) pixels within the highest 25th percentile of diffuse excess light and lowest 75th percentile of chronic noise (higher excess light, lower noise). We used RF models with 500 trees using a $2 \%$ data-withhold (out-of-bag OOB) sample due to the large sample size. Because binary response variables were zero-inflated, we controlled for imbalance by drawing an equal sample size (1\%) of data from zeros and non-zeros. To control for random fluctuations in variable importance across forests, we ran RF models 50 times and took a mean of resulting importance values for each variable (Anderson et al. 2017). We consider variables with the highest increase in percent MSE to be the most important.

\section{Results}

\section{Distribution of ALN}

Across NPS land, we found low rates of overlapping light and noise pollution, with $82.5 \%$ of pixels experiencing little localized light and less than doubling of transient noise conditions and $87.1 \%$ experiencing less than doubling of diffuse light and chronic noise conditions. By our threshold criteria, we found that parks generally had more dark than quiet areas. Of all pixels on NPS land, $4.7 \%$ experienced diffuse light greater than double background conditions and $2.8 \%$ experienced some localized light, while chronic and transient noise exceedance was greater than double background conditions in 11.4 and $17.1 \%$ of all pixels on NPS land (Fig. 1).

Of the $62 \%(n=197)$ of park units that experienced diffuse light greater than double background conditions within some portion of the park, the majority experienced these levels in less than 5\% of the park's area (Table S1), indicating that high levels of diffuse excess light conditions occurred in small areas. Among park units experiencing diffuse light greater than double background conditions within their boundaries, $4.6 \%(n=9)$ had no detectable localized light. For these parks, and many others with low localized light, most of the excess light originates from sources outside the park boundaries. Conversely, in park units experiencing diffuse light less than double of background conditions, about a third (32.8\%, $\mathrm{n}=119$ ) had non-zero localized light values. In these parks, views of the night sky are relatively unobstructed, but they contain lighting from localized sources within the park boundaries.

In contrast to generally dark conditions within parks, $>95 \%$ of national park units experienced both chronic and transient noise exceedance greater than double background conditions within some portion of the park.

Despite a low percentage of pixels with high noise and excess light, a large proportion of park units had median excess light and median noise equal to or greater than double background conditions $(41.5 \%$ diffuse-chronic and $43.5 \%$ localized-transient; Fig. 2). This discrepancy is due to the large number of small parks $\left(<2 \mathrm{~km}^{2}\right)$ with high noise and excess light conditions (81.5 and $82.5 \%$ of small parks). Many park units had low median excess light and low median noise for both diffuse-chronic $(43.1 \%)$ and localized-transient (42.5\%) ALN conditions (Fig. 2). Few parks had low excess light but high noise or low noise and high excess for both diffuse-chronic and localized-transient ALN conditions (1-15\%, Fig. 2).

\section{Correlation between ALN}

We found a weak linear relationship between diffuse light and chronic noise $\left(R=0.20\right.$ and $\mathrm{R}^{2}=0.21$; 


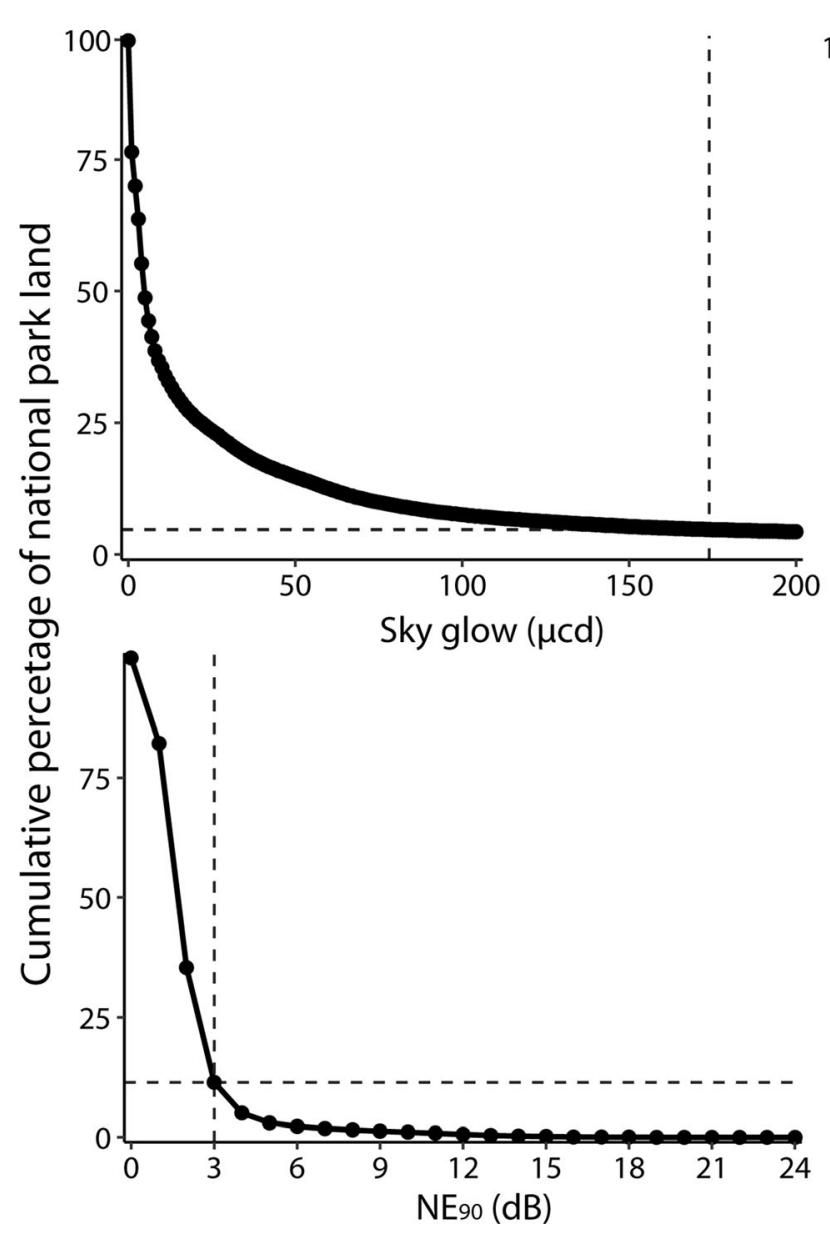

Fig. 1 Cumulative percentage of pixels in national park land in the contiguous US with each level of excess light (top panels) and noise exceedance (bottom panels). Panels on the right indicate localized-transient light and noise conditions (upward radiance from VIIRS $\mathrm{nW} \mathrm{cm}{ }^{-2} \mathrm{sr}^{-1}$; and $\mathrm{NE}_{10} \mathrm{~dB}$ ) and panels on the left indicate diffuse-chronic conditions (sky glow $\mu \mathrm{cd}$;

Fig. 3). The relationship between diffuse-chronic ALN conditions best fit a third order polynomial model $\left(\mathrm{R}^{2}=0.65\right)$. When we subset the data into park unit type (natural resource parks, cultural parks, recreation areas, and national monuments), ALN had the highest correlation in cultural parks $(R=0.81$ and $\left.\mathrm{R}^{2}=0.58\right)$ and the lowest in natural resource parks $\left(R=0.07\right.$ and $\left.\mathrm{R}^{2}=0.04\right)$.

Within each park unit, there was a higher positive correlation between diffuse-chronic ALN and a greater probability of positive correlation with a higher density of major roads (Table S2). There was a higher positive correlation between diffuse-chronic ALN in parks closer to an urban area and with more

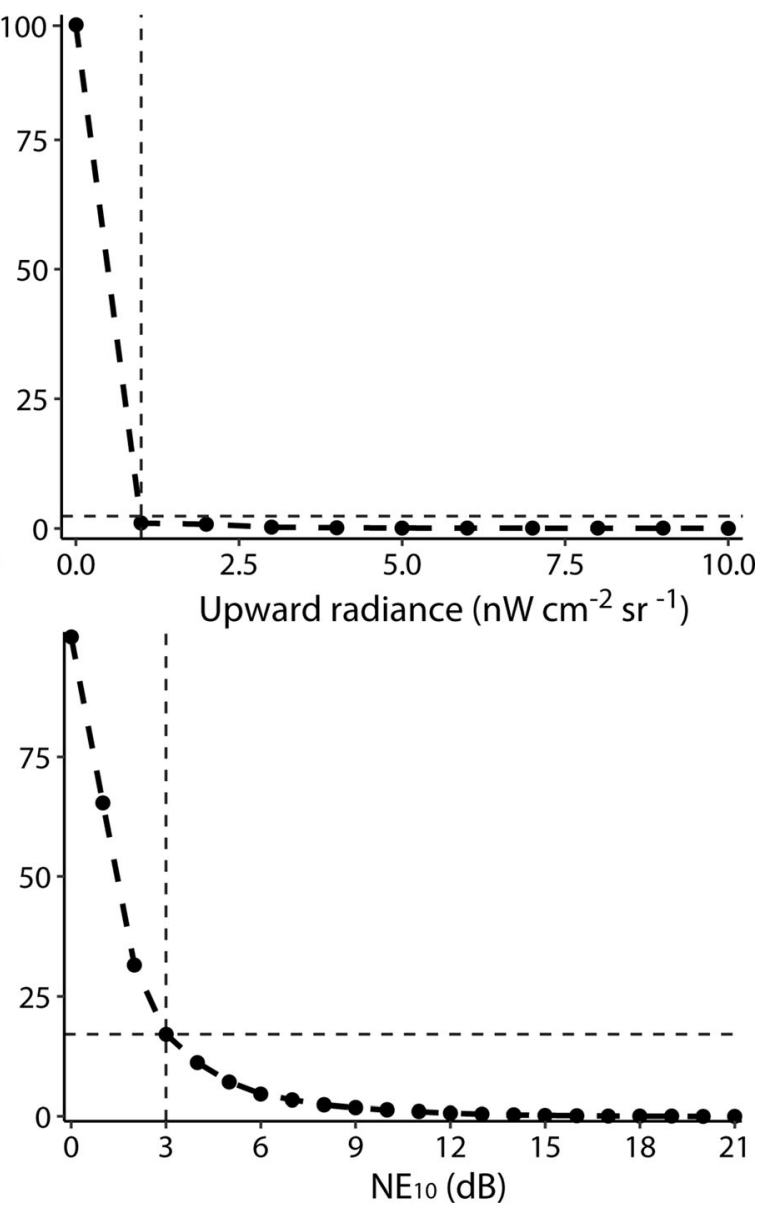

and $\mathrm{NE}_{90} \mathrm{~dB}$ ). Dashed horizontal and vertical lines indicate the cumulative percentage of National Park Service land experiencing doubling of natural conditions (or non-zero VIIRS) due to light and noise. Y-axes of top panels are limited for visualization purposes (actual range of sky glow 0-24,691 $\mu \mathrm{cd}$ and upward radiance $0-253 \mathrm{nW} \mathrm{cm}^{-2} \mathrm{sr}^{-1}$ )

aircraft traffic. There was a greater probability of positive correlation between diffuse-chronic ALN in park types other than natural resource parks and recreation areas, and closer to development (Table S2).

Landscape drivers of ALN co-occurrence and divergence

For diffuse-chronic conditions, the top landscape features that predicted high probability of co-occurrence of ALN in individual pixels included closer proximity to an urban area, high overhead flight traffic, and closer proximity to a petroleum refinery (Fig. 4). 


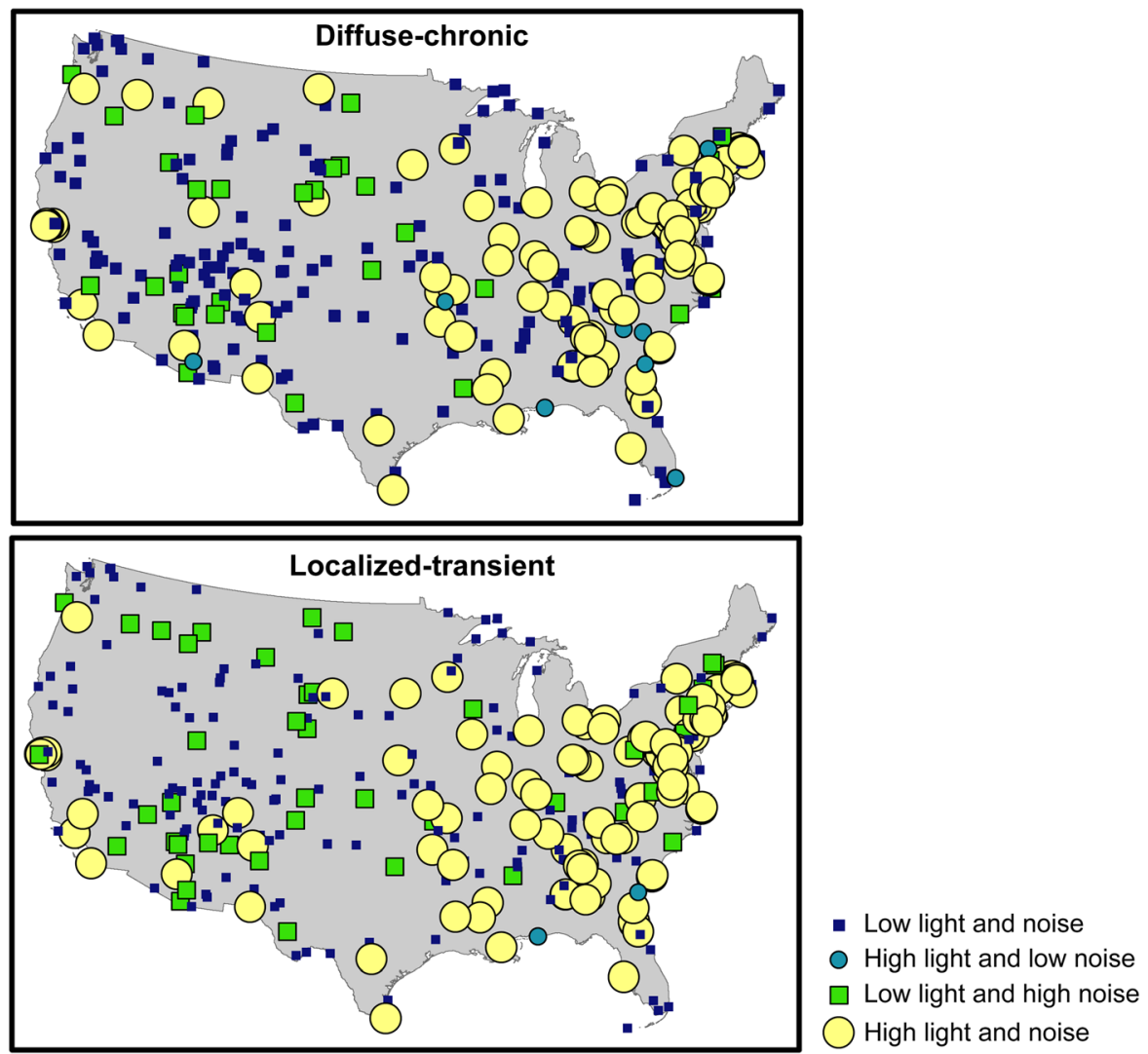

Fig. 2 The co-occurrence and divergence of high median light and noise conditions in each national park unit. The top panel indicates diffuse excess light (sky glow, $\mathrm{nW} \mathrm{cm} \mathrm{cm}^{-2} \mathrm{sr}^{-1}$ ) and chronic noise exceedance conditions $\left(\mathrm{NE}_{90} \mathrm{~dB}\right)$ and the bottom panel indicates localized excess light (upward radiance from VIIRS, $\mathrm{nW} \mathrm{cm}^{-2} \mathrm{sr}^{-1}$ ) and transient noise conditions $\left(\mathrm{NE}_{10}\right.$

These same three landscape features also predicted the occurrence of higher excess light and lower noise conditions. To better understand these patterns, we summarized the proportion of park area at increasing distances from urban areas with doubling of both diffuse excess light and chronic noise and doubling of diffuse excess light but not chronic noise. We found $99 \%$ of pixels within urban areas experienced cooccurrence of doubling of excess light and noise (Fig. 5). The highest percentage of pixels with doubling of excess light and lower noise conditions (10\%) occurred 5-20 km from urban areas (Fig. 5).

The top landscape features that predicted lower diffuse excess light and higher chronic noise included the presence of a road, closer proximity to developed land, and closer proximity to an oil and gas well (Fig. 4). In pixels with a road present, 25\%
$\mathrm{dB})$. For localized light, high median values in park units were $>0$ and low median values were $=0$. For diffuse light and for noise conditions, high and low levels were determined if median values in park units were above or below doubling of natural conditions (sky glow $174 \mu \mathrm{cd} ; \mathrm{NE}_{10}$ and $\mathrm{NE}_{90} 3 \mathrm{~dB}$ )

experienced lower excess light and higher noise conditions (Fig. 5).

\section{Discussion}

Light and noise pollution are emerging as major issues for wildlife conservation (Gaston et al. 2014; Buxton et al. 2017) and human health and wellbeing (Chepesiuk 2009; Basner et al. 2014). While the cumulative effects of multiple stressors are increasingly a focus in ecological research, few attempts have been made to look at how excess light and noise are related across landscapes, despite the recognized importance of each in isolation. We addressed this gap through our analysis of ALN in U.S. national park lands. We found that most U.S. national park lands experience 


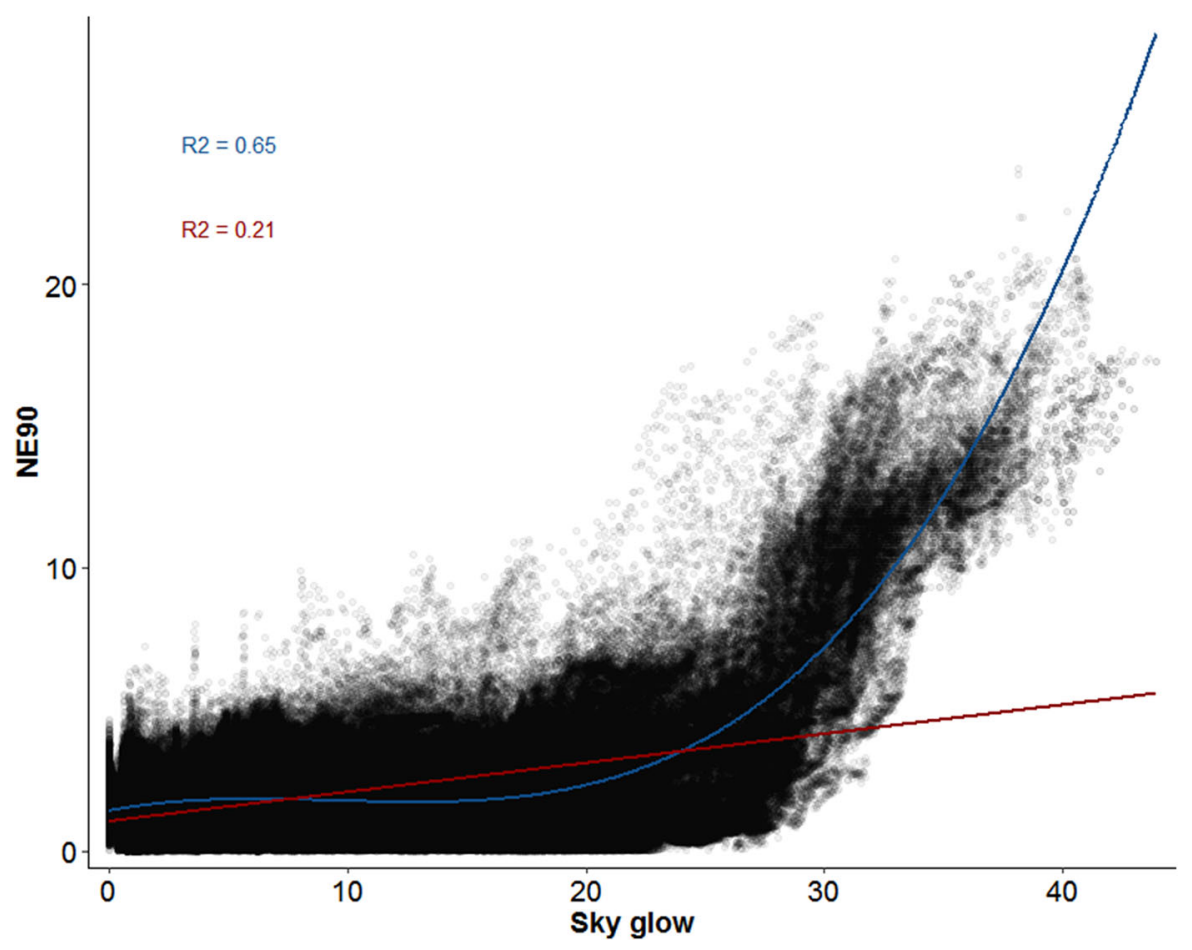

Fig. 3 The linear and non-linear relationship between anthropogenic noise and light in national parks: linear (dark grey) and third order polynomial relationship (light grey) between chronic

overlapping dark and quiet conditions. Where excess light or noise exist, they do not strongly covary within U.S. national park land, particularly in natural resource parks and in parks with low rates of traffic and development within park boundaries.

While noise conditions have been documented in U.S. protected areas (), excess light conditions in national park units have not been reported. There were few areas within parks with significant, detectable localized anthropogenic lighting sources. Exceptions included parks adjacent to major urban centers, such as the Santa Monica Mountains National Recreation Area near Los Angeles and Lake Mead National Recreation Area near Las Vegas (Table S1). However, we also identified relatively remote parks with smaller concentrated areas of high localized excess light, such as Big Thicket National Preserve and Colorado National Monument, where point sources of lighting in an otherwise dark park may represent situations where light mitigation could improve conditions. Similarly, there were few areas in parks where diffuse excess light was greater than double background light conditions. However, our analysis of diffuse light noise exceedance $\left(\mathrm{NE}_{90} \mathrm{~dB}\right)$ and diffuse excess light (sky glow $\mu \mathrm{cd})$. The grey lines are model fit between noise and light values

pollution is likely an underestimate, given we used a threshold of $174 \mu \mathrm{cd}$ because it parallels the threshold used for noise, yet there are several species known to be impacted by any excess light above natural levels (Seymoure et al. 2019). Finally, we identified 119 parks with low diffuse light and some measurable localized excess light. These parks enjoy good conditions for viewing the night sky, but bright localized lighting represent opportunities for parks to reduce lighting inside park boundaries.

We found very little area overall in national parks within the contiguous U.S. with overlapping high ALN conditions. This affirms prior findings that NPS units tend to have lower exposure to noise and light relative to other protected areas (Buxton et al. 2017; Seymoure et al. 2019). However, when we took a median of ALN conditions in each park unit, we found a high number of parks with median excess light and noise greater than double background conditions. This discrepancy results from the large number of small NPS units $\left(<2 \mathrm{~km}^{2}\right)$ within or adjacent to cities that are inundated with high noise and excess light. 


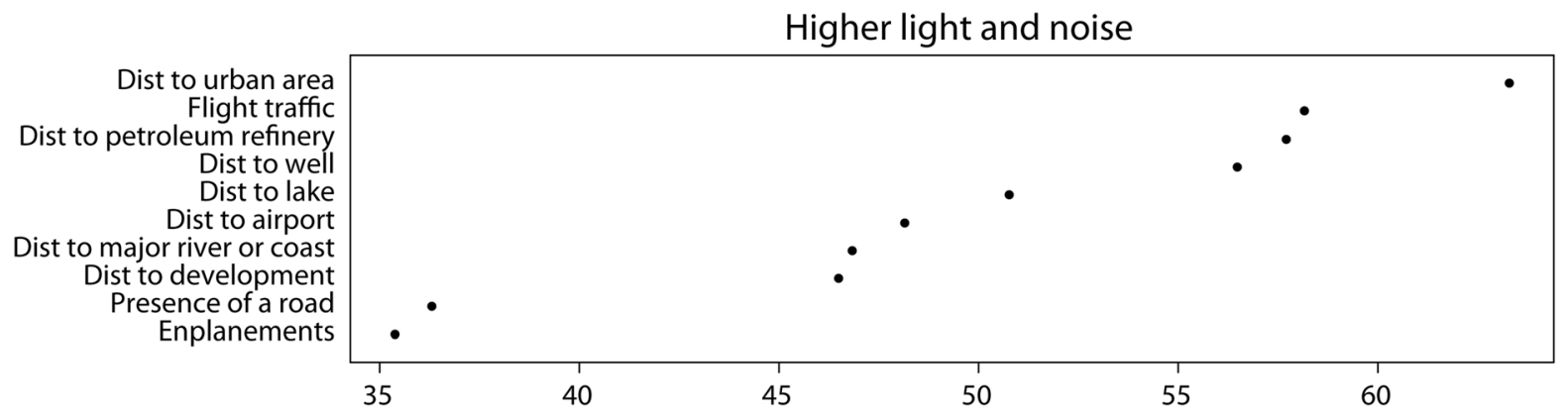

Higher light and lower noise

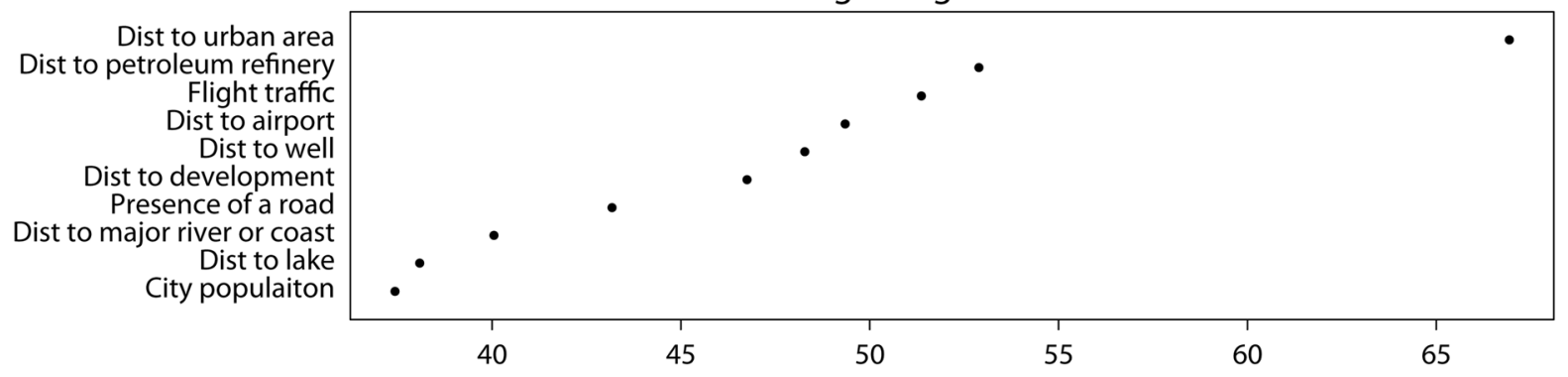

Lower light and higher noise

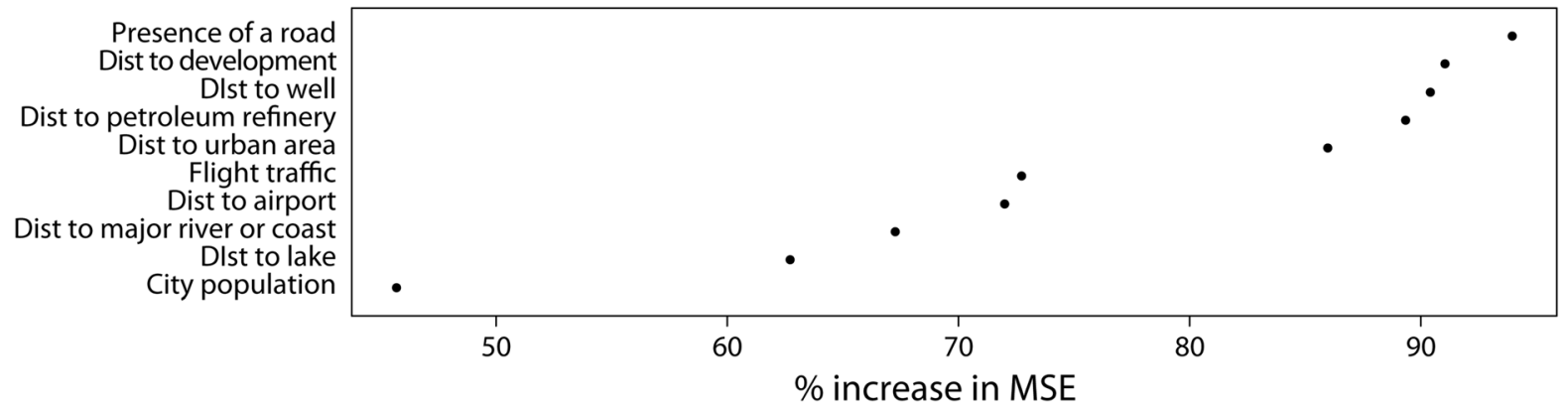

Fig. 4 Importance of landscape covariates in a random forest model indicated by mean percent increase in mean squared error (MSE): (top panel) for binomial models examining the cooccurrence of higher excess light and noise, (mid panel) the occurrence of higher excess light and lower noise, and (lower panel) the occurrence of lower excess light and higher noise. Higher and lower light and noise were characterized if pixels

We found that across park land there was low correlation between all types of ALN conditions. Part of this low correlation is explained by nonlinearitywe found a significant third order polynomial relationship between diffuse-chronic ALN conditions. This was contrary to our expectation that ALN would overlap because many human activities produce both noise and light and because noise and light models had VIIRS radiance as common inputs. Thus, the lack of correlation and third-order polynomial relationship likely reflects the different ways in which light and were above or below the top 25th percentiles. Greater MSE indicates a larger loss of predictive accuracy when covariates are permuted and thus a larger influence of landscape covariates on the co-occurrence or divergence of noise and excess light. Results are shown for covariates with the top 10 largest MSE for display purposes. Only diffuse-chronic light and noise conditions were compared (sky glow $\mu \mathrm{cd}$ and $\mathrm{NE}_{90} \mathrm{~dB}$ )

sound propagate across a landscape. Sound and light interact in different ways with biophysical features. Moreover, atmospheric propagation attenuates sound much more rapidly than light (Piercy et al. 1977; Duriscoe et al. 2018). This may drive divergence between ALN, where light may spread longer distances from dense urban areas in the form of sky glow. We found the greatest correlation between ALN in parks designated to preserve cultural or historic resources, likely because these parks are more often within or near cities. When we examined the effect of 

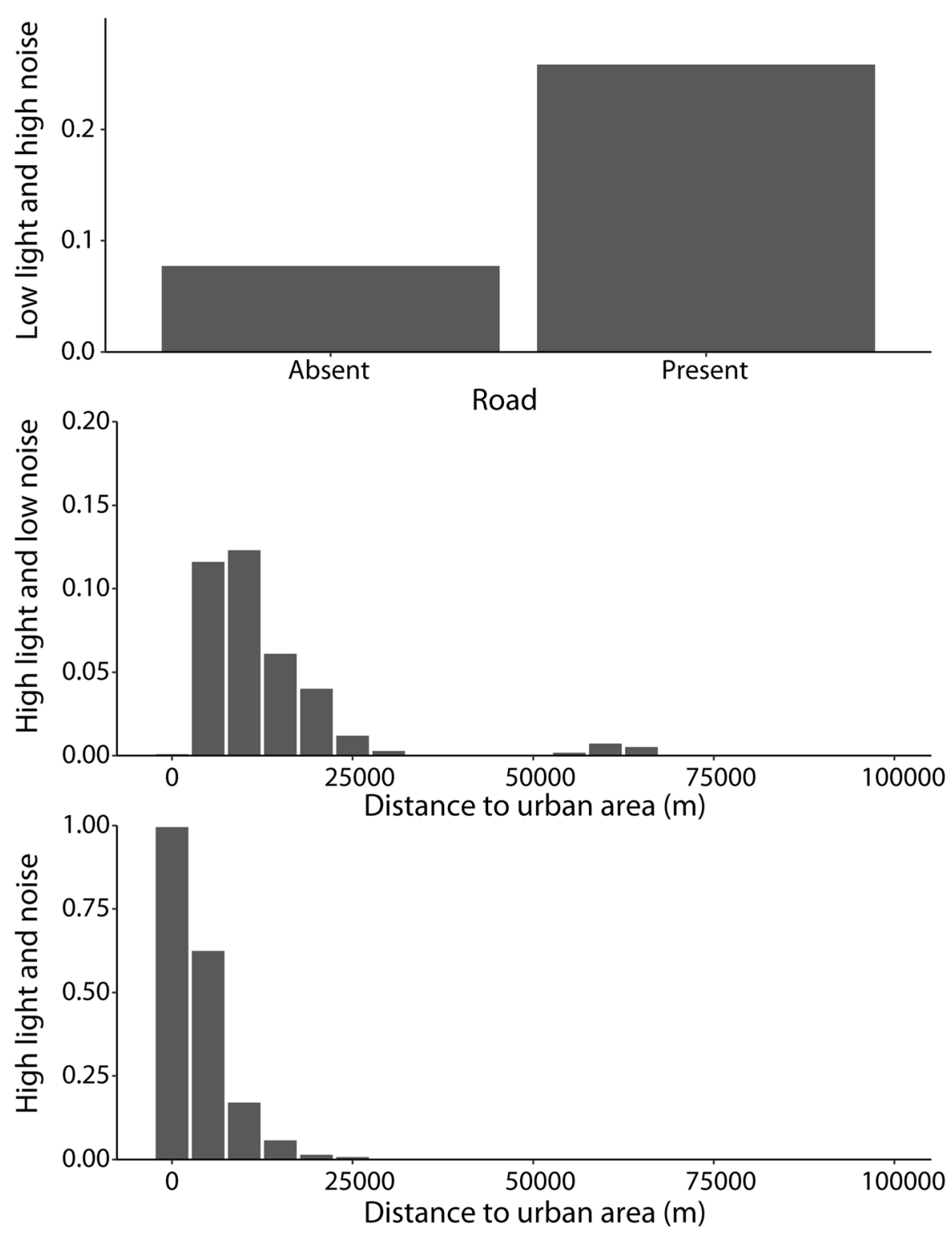

Fig. 5 The proportion of pixels with co-occurring and diverging high anthropogenic light and noise compared to the top landscape drivers. The top panel indicates the proportion of pixels with low diffuse light and high chronic noise exceedance in areas with roads present versus absent. The mid panel shows the proportion of pixels with high diffuse light and low chronic noise exceedance at increasing distance ranges from urban areas, and the bottom panel the co-occurrence of high diffuse

other landscape features, we found that the density of roads, the type of road, distance to urban areas and development, flight traffic, and the park type all contributed to the positive correlation between ALN in park units. light and chronic noise exceedance at increasing distance ranges from urban areas. High and low light and noise were characterized if pixels were above or below doubling of natural conditions (diffuse light $>$ or $<174 \mu \mathrm{cd}$ and chronic noise $>$ or $<3 \mathrm{~dB}$ ). The first bar includes 0 values only rather than a range of values. Distance to urban area on $\mathrm{X}$-axes are limited for visualization purposes only (actual range of distance to urban areas $0-145,382.7 \mathrm{~m}$ )

In pixels across all park land, we found that proximity to an urban area, high overhead flight traffic, and proximity to a petroleum refinery predicted areas with co-occurrence of higher chronic-diffuse ALN. As expected, due to high levels of human 
activity, park areas that were within urban areas experienced the highest levels of co-occurring higher ALN. Park areas that were within 5-20 km of an urban area had the highest levels of divergence between ALN, with higher excess light and lower noise levels. The presence of a road, distance to developed land, and distance to an oil and gas well also predicted divergence between ALN. Because many roads in parks are remote without street lights, approximately $25 \%$ of park areas adjacent to a road experienced higher noise but lower excess light conditions.

The co-occurrence and divergence of ALN have implications for conservation and the management of dark skies and natural sounds in protected areas. An ongoing challenge in conservation biology is to understand the interactive and independent effects of multiple anthropogenic stressors (Fleishman et al. 2011). Although the mechanistic understanding of the interactive effects of sensory pollutants on wildlife are in their infancy, light and noise pollution have been demonstrated to jointly affect individual animal behavior (in controlled experimental settings; Chan et al. 2010) and host-parasite interactions (McMahon et al. 2017). Conversely, other evidence demonstrates that animals may be affected by light or noise pollution individually (Da Silva et al. 2014; DoradoCorrea et al. 2016). Thus, when more than one sensory pollutant is present, the response of different species may change in complex and, as-of-yet, unpredictable ways (Dominoni et al. 2020). Similarly, humans respond to anthropogenic light and noise, where both of these pollutants affect sleep (Cho et al. 2013; Halperin 2014) and visitor appreciation of natural areas (Rapoza et al. 2014; Benfield et al. 2018). Yet the combined impacts of both sensory pollutants on human wellbeing in natural settings are unclear. By taking advantage of the relatively independent spatial variation of noise and excess light identified in our study, future research can work to disentangle the separate and combined effects of multiple sensory pollutants.

In park areas where noise and excess light overlap coordinated approaches to manage both pollutants may be most effective. For example, management of one pollutant may be counter-productive if noise and light have antagonistic effects (Miller 2006; Fuller et al. 2007). Moreover, while chronic noise generally inhibits auditory perception, chronic excess light often enhances visual perception, with potential for elevated predation rates (Minnaar et al. 2015). In these cases, reducing only one source of pollution could lead to unexpected outcomes for wildlife given complex interactions between sensory modalities. Urban areas, where noise and excess light are correlated, present formidable challenges for restoring acoustic and photic resources. Areas where noise and light were decoupled in space (e.g., areas near roads) in the national park system may represent tractable areas for management, as only one stressor needs to be addressed at a time. Finally, parks that are generally free from excess light and noise- the iconic natural resource parks in the system-represent important refuges for wildlife and human experience, where efforts could focus on maintaining such pristine conditions.

Our findings highlight the significance of geographic context for NPS management options of noise and excess light. For example, park areas with low levels of excess light and higher noise were often adjacent to roads. For these areas, designing or revising transportation plans or park infrastructure (e.g., shuttle systems, quiet pavement) are promising options (Lynch et al. 2011). Areas with high levels of excess light and low noise tended to be associated with sources outside park boundaries. These scenarios will require park units to work with nearby communities to reduce the unintended illumination of the park by outdoor lighting. Outreach and education regarding the benefits of reducing excess light for human and wildlife health can lead to constructive partnerships (Kyba et al. 2017). As the impact of sensory pollutants on organisms becomes increasingly clear, their interactive effects in protected areas are a critical concern for conservation.

Acknowledgements We thank members of the SALET Lab for helpful discussions. Thanks to G. Bastille-Rousseau and D. Machovec for assistance with the CU supercomputer. This work utilized resources from the University of Colorado Boulder Research Computing Group, which is supported by the National Science Foundation (Awards ACI-1532235 and ACI-1532236), the University of Colorado Boulder, and Colorado State University. Funding for this work was supported by the National Park Service Natural Sounds and Night Skies Division and ExxonMobil Production/XTO Energy. We thank two anonymous reviewers for their helpful comments.

Open Access This article is licensed under a Creative Commons Attribution 4.0 International License, which permits use, sharing, adaptation, distribution and reproduction in any medium or format, as long as you give appropriate credit to the 
original author(s) and the source, provide a link to the Creative Commons licence, and indicate if changes were made. The images or other third party material in this article are included in the article's Creative Commons licence, unless indicated otherwise in a credit line to the material. If material is not included in the article's Creative Commons licence and your intended use is not permitted by statutory regulation or exceeds the permitted use, you will need to obtain permission directly from the copyright holder. To view a copy of this licence, visit http://creativecommons.org/licenses/by/4.0/.

\section{References}

Andersson M (1994) Sexual selection. Princeton University Press, Princeton

Anderson J, Burns PJ, Milroy D, Ruprecht P, Hauser T, Siegel HJ (2017) Deploying RMACC Summit: an HPC resource for the Rocky Mountain region. In: PEARC17, New Orleans, LA, USA. https://doi.org/10.1145/3093338. 3093379

Barber JR, Crooks KR, Fristrup KM (2010) The costs of chronic noise exposure for terrestrial organisms. Trends Ecol Evol 25:180-189

Bartoń K (2013) MuMIn: multi-model inference. R package version 1.9.0. https://CRAN.R-project.org/package= MuMIn

Basner M, Babisch W, Davis A, Brink M, Clark C, Janssen S, Stansfeld S (2014) Auditory and non-auditory effects of noise on health. Lancet 383:1325-1332

Benfield JA, Nutt RJ, Taff BD, Miller ZD, Costigan H, Newman P (2018) A laboratory study of the psychological impact of light pollution in national parks. J Environ Psychol 57:67-72

Breiman L (2001) Random forests. Mach Learn 45:5-32

Brumm H (2013) Animal communication and noise. Springer, Berlin

Burnham KP, Anderson DR (2002) Model selection and multimodel inference: a practical information-theoretic approach, 2nd edn. Springer, New York

Buxton RT, McKenna MF, Brown E, Mennitt DJ, Fristrup K, Crooks K, Angeloni L, Wittemyer G (2019) Anthropogenic noise in US national parks-sources and spatial extent. Front Ecol Environ. https://doi.org/10.1002/fee.2112

Buxton RT, McKenna MF, Mennitt DJ, Fristrup KM, Crooks K, Angeloni LM, Wittemyer G (2017) Noise pollution is pervasive in U.S. protected areas. Science 356:531-533

Červený J, Begall S, Koubek P, Nováková P, Burda H (2011) Directional preference may enhance hunting accuracy in foraging foxes. Biol Lett 7:355-357

Chan AAY-H, Blumstein DT (2011) Attention, noise, and implications for wildlife conservation and management. Appl Anim Behav Sci 131:1-7

Chan AAY-H, Giraldo-Perez P, Smith S, Blumstein DT (2010) Anthropogenic noise affects risk assessment and attention: the distracted prey hypothesis. Biol Lett 6:458-461

Chepesiuk R (2009) Missing the dark: health effects of light pollution. Environ Health Perspect 117:A20-A27
Cho JR, Joo EY, Koo DL, Hong SB (2013) Let there be no light: the effect of bedside light on sleep quality and background electroencephalographic rhythms. Sleep Med 14:1422-1425

Comay LB (2013) National park system: what do the different park titles signify? Management and Policy Considerations, National Parks, pp. 65-86

Da Silva A, Samplonius JM, Schlicht E, Valcu M, Kempenaers B (2014) Artificial night lighting rather than traffic noise affects the daily timing of dawn and dusk singing in common European songbirds. Behav Ecol 25:1037-1047

Davies TW, Bennie J, Inger R, Gaston KJ (2013) Artificial light alters natural regimes of night-time sky brightness. Sci Rep 3:1722

Dominoni DM, Halfwerk W, Baird E, Buxton RT, FernándezJuricic E, Fristrup KM, McKenna MF, Mennitt DJ, Perkin EK, Seymoure BM, Stoner DC, Tennessen JB, Toth CA, Tyrrell LP, Wilson A, Francis CD, Carter NH, Barber JR (2020) Why conservation biology can benefit from sensory ecology. Nat Ecol Evol. https://doi.org/10.1038/s41559020-1135-4

Dorado-Correa AM, Rodríguez-Rocha M, Brumm H (2016) Anthropogenic noise, but not artificial light levels predicts song behaviour in an equatorial bird. R Soc Open Sci 3:160231

Duriscoe DM, Anderson SJ, Luginbuhl CB, Baugh KE (2018) A simplified model of all-sky artificial sky glow derived from VIIRS Day/Night band data. J Quant Spectrosc Radiat Transf 214:133-145

Elvidge CD, Baugh K, Zhizhin M, Hsu FC, Ghosh T (2017) VIIRS night-time lights. Int J Remote Sens 38:5860-5879

Eidson L (2015) Wilderness areas version 10.12.15. Wilderness.net. University of Montana's Wilderness Institute, Missoula, USA

ESRI (2014) World Cities. https://www.arcgis.com/home/item. html?id=02901a9c1d624f50bf7fab6270d4f233. Accessed 16 June 2016

Evans J, Murphy M (2017) rfUtilities. R package version 2.1-0. https://cran.r-project.org/package=rfUtilities

Falchi F, Cinzano P, Duriscoe D, Kyba CCM, Elvidge CD, Baugh K, Portnov BA, Rybnikova NA, Furgoni R (2016) The new world atlas of artificial night sky brightness. Sci Adv 2:e1600377

Fay RR, Popper AN (2000) Evolution of hearing in vertebrates: the inner ears and processing. Hear Res 149:1-10

Fleishman E, Blockstein DE, Hall JA, Mascia MB, Rudd MA, Scott JM, Sutherland WJ, Bartuska AM, Brown AG, Christen CA, Clement JP, Dellasala D, Duke CS, Eaton M, Fiske SJ, Gosnell H, Haney JC, Hutchins M, Klein ML, Marqusee J, Noon BR, Nordgren JR, Orbuch PM, Powell J, Quarles SP, Saterson KA, Savitt CC, Stein BA, Webster MS, Vedder A (2011) Top 40 priorities for science to inform US conservation and management policy. Bioscience 61:290-300

Francis C, Barber JR (2013) A framework for understanding noise impacts on wildlife: an urgent conservation priority. Front Ecol Environ 11:305-313

Fuller RA, Warren PH, Gaston KJ (2007) Daytime noise predicts nocturnal singing in urban robins. Biol Lett $3: 368-370$ 
Gagliano M, Grimonprez M, Depczynski M, Renton M (2017) Tuned in: plant roots use sound to locate water. Oecologia 184:151-160

Gaston KJ, Bennie J, Davies TW, Hopkins J (2013) The ecological impacts of nighttime light pollution: a mechanistic appraisal. Biol Rev 88:912-927

Gaston KJ, Davies TW, Bennie J, Hopkins J (2012) Reducing the ecological consequences of night-time light pollution: options and developments. J Appl Ecol 49:1256-1266

Gaston K, Duffy J, Gaston S, Bennie J, Davies T (2014) Human alteration of natural light cycles: causes and ecological consequences. Oecologia 176:917-931

Halfwerk W, Slabbekoorn H (2015) Pollution going multimodal: the complex impact of the human-altered sensory environment on animal perception and performance. Biol Lett 11:20141051

Halperin D (2014) Environmental noise and sleep disturbances: a threat to health? Sleep Sci 7:209-212

Hettena AM, Munoz N, Blumstein DT (2014) Prey responses to predator's sounds: a review and empirical study. Ethology 120:427-452

Hölker F, Moss T, Griefahn B, Kloas W, Voigt C, Henckel D, Hänel A, Kappeler P, Voelker S, Schwope A, Franke S, Uhrlandt D, Fischer J, Klenke R, Wolter C, Tockner K (2010) The dark side of light: a transdisciplinary research agenda for light pollution policy. Ecol Soc 15:1-13

Johnsen S (2012) The optics of life: a biologist's guide to light in nature. Princeton University Press, Princeton

Kyba CCM, Kuester T, Sánchez de Miguel A, Baugh K, Jechow A, Hölker F, Bennie J, Elvidge CD, Gaston KJ, Guanter L (2017) Artificially lit surface of Earth at night increasing in radiance and extent. Sci Adv 3:E1701528

Lang AB, Kalko EKV, Römer H, Bockholdt C, Dechmann DKN (2006) Activity levels of bats and katydids in relation to the lunar cycle. Oecologia 146:659-666

Liaw A, Wiener M (2002) Classification and regression by randomForest. R News 2:18-22

Lynch E, Joyce D, Fristrup K (2011) An assessment of noise audibility and sound levels in U.S. National Parks. Landsc Ecol 26:1297-1309

McMahon TA, Rohr JR, Bernal XE (2017) Light and noise pollution interact to disrupt interspecific interactions. Ecology 98:1290-1299

Mennitt DJ, Fristrup KM (2016) Influence factors and spatiotemporal patterns of environmental sound levels in the contiguous United States. Noise Control Eng J 64:342-353

Mennitt D, Sherrill K, Fristrup K (2014) A geospatial model of ambient sound pressure levels in the contiguous United States. J Acoust Soc Am 135:2746-2764

Miller MW (2006) Apparent effects of light pollution on singing behavior of American robins. Condor 108:130-139, 110

Minnaar C, Boyles JG, Minnaar IA, Sole CL, McKechnie AE (2015) Stacking the odds: light pollution may shift the balance in an ancient predator-prey arms race. J Appl Ecol 52:522-531

Montgomerie R, Weatherhead PJ (1997) How robins find worms. Anim Behav 54:143-151

National Park Service (2003) Nomenclature of park system areas. National Park Service. https://www.nps.gov/ parkhistory/hisnps/NPSHistory/nomenclature.html. Accessed 5 July 2016
National Park Service (2006) National park service management policies. NPS. https://www.nps.gov/policy/mp2006. pdf. Accessed 20 March 2015

National Park Service (2015) Annual recreation visitation by Park (1979 - Last Calendar Year). https://irma.nps.gov/ Stats/SSRSReports/National\%20Reports/Annual\% 20Recreation $\% 20$ Visitation $\% 20 \mathrm{By} \% 20 \mathrm{Park} \% 20(1979 \%$ 20-\%20Last\%20Calendar\%20Year. Accessed 20 June 2016

National Park Service (2016) Administrative boundaries of national park system units-National Geospatial Data Asset (NGDA) NPS National Parks Dataset. NPS: Land Resources Division. https://irma.nps.gov/DataStore/ Reference/Profile/2224545? lnv=True. Accessed 3 March 2016

Piercy JE, Embleton TFW, Sutherland LC (1977) Review of noise propagation in the atmosphere. J Acoust Soc Am 61:1403-1418

R Core Team (2019) R: a language and environment for statistical computing. R Foundation for Statistical Computing, Vienna. https://www.R-project.org/

Rapoza A, Sudderth E, Lewis K, Lee C, Hastings A (2014) Aircraft dose-response relations for day-use visitors to backcountry areas in National Parks. J Acoust Soc Am 135:2405-2406

Rich C, Longcore T (2006) Ecological consequences of artificial night lighting. Island Press, Washington, DC

Schielzeth H (2010) Simple means to improve the interpretability of regression coefficients. Methods Ecol Evol 1:103-113

Seymoure B, Buxton R, White J, Linares C, Fristrup K, Crooks K, Wittemyer G, Angeloni LM (2019) Anthropogenic light disrupts natural light cycles in critical conservation areas. Preprint at SSRN. https://ssrn.com/abstract=3439670

Shannon G, McKenna MF, Angeloni LM, Crooks KR, Fristrup KM, Brown E, Warner KA, Nelson MD, White C, Briggs J, McFarland S, Wittemyer G (2016) A synthesis of two decades of research documenting the effects of noise on wildlife. Biol Rev Camb Philos Soc 91:982-1005

Sih A, Ferrari MCO, Harris DJ (2011) Evolution and behavioural responses to human-induced rapid environmental change. Evol Appl 4:367-387

Swaddle JP, Francis CD, Barber JR, Cooper CB, Kyba CCM, Dominoni DM, Shannon G, Aschehoug E, Goodwin SE, Kawahara AY, Luther D, Spoelstra K, Voss M, Longcore T (2015) A framework to assess evolutionary responses to anthropogenic light and sound. Trends Ecol Evol 30:550-560

U.S. Census Bureau (2015a) TIGER/Line urban areas cartographic boundary file. https://catalog.data.gov/dataset/ tiger-line-shapefile-2015-2010-nation-u-s-2010-censusurban-area-national. Accessed 15 June 2016

U.S. Census Bureau (2015b) TIGER/Line roads database. https://www.census.gov/geo/maps-data/data/tigergeodatabases.html. Accessed 15 June 2016

Publisher's Note Springer Nature remains neutral with regard to jurisdictional claims in published maps and institutional affiliations. 